\title{
APLICAÇÃO DO SCRUMNO DESENVOLVIMENTO DA PROPOSTA DE TRABALHO DO PROJETO RONDON NA VISÃO DE UM RONDONISTA UNIVERSITARIO
}

\author{
Eliel Sousa Santos \\ Faculdade de Tecnologia de Jundiaí - Deputado Ary Fossen \\ eliel.sousat28@gmail.com \\ Adani Cusin Sacilotti \\ Faculdade de Tecnologia de Jundiaí - Deputado Ary Fossen \\ prof.adani@fatecjd.edu.br
}

\section{Resumo}

Este artigo consiste em um breve estudo sobre a metodologia de gerenciamento de projetos Scrum, suas práticas e aplicações, e um breve relato sobre o desenvolvimento da proposta de trabalho do Projeto Rondon dentro da Faculdade de Tecnologia de Jundiaí - Deputado Ary Fossen. Observou-se a necessidade de implantar uma metodologia de gerenciamento de projetos, que abordasse aspectos logísticos, organizacionais e cronológicos atrelados às etapas de seu desenvolvimento. Desta forma, os processos foram expostos e mostraram de que forma a implantação da metodologia de gerenciamento de projetos ágeis Scrum foi implementada, seu desenvolvimento e dificuldades enfrentadas. O objetivo de utilizar essa metodologia está na busca de tornar os processos mais iterativos e eficientes, o que também contribui para que esta proposta apresente melhor qualidade nos seus resultados. Diante disso, foi possível concluir que esta é uma preocupação constante, pois a instituição não disponibilizava de muitas verbas, necessitando de um bom gerenciamento de ações para o seu sucesso na prática.

Palavras-chave: Projeto de Extensão. Desenvolvimento. Gerenciamento de Projeto. Metodologias Ágeis. Integração

\section{SCRUM FOR DEVELOPMENT OF PROPOSED RONDON PROJECT WORK IN A RONDONISTA UNIVERSITY VISION}

\begin{abstract}
This article consists of a brief study on the project management methodology Scrum, practices and applications, and a brief account of the development of the proposed work of the Rondon Project in the Jundiai Technology Faculty - Mr Ary Fossen. There was the need to implement a project management methodology that addressed logistical, organizational and chronological aspects linked to the stages of its development. Thus, the processes were exposed and showed how the implementation of agile project management methodology Scrum has been implemented, its development and difficulties faced. The goal of using this methodology is seeking to make them more efficient and iterative processes, which also contributes to this proposal presents the best quality in their results. Therefore, it was concluded that this is a constant concern because the institution did not make available from many funds, requiring a good management actions for their success in practice..
\end{abstract}

Keywords: Extension project. Development. Project Management. Agile methodologies. Integration 


\section{EXIENESHI

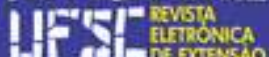

\section{SCRUM PARA EL DESARROLLO DEL PROYECTO DE TRABAJO DEL PROYECTO RONDON EN UNA VISIÓN RONDONISTA ACADÉMICO}

\section{Resumen}

Este artículo consta de un breve estudio sobre la metodología de gestión de proyectos Scrum, prácticas y aplicaciones, y una breve reseña del desarrollo de la propuesta de trabajo del Proyecto Rondon en la Facultad de Tecnología de Jundiaí - Ary Fossen. No había la necesidad de implementar una metodología de gestión de proyectos que abordó aspectos logísticos, organizativos y cronológicos relacionados con las etapas de su desarrollo. Por lo tanto, los procesos fueron expuestos y mostraron cómo se ha implantado la aplicación de la metodología de gestión de proyectos ágiles Scrum, su desarrollo y dificultades encontradas. El objetivo de la utilización de esta metodología está tratando de hacer que los procesos sean más eficientes e iterativos, lo que contribuye también a esta propuesta presenta la mejor calidad en sus resultados. Por lo tanto, se concluyó que esto es una preocupación constante porque la institución no poner a disposición de muchos fondos, lo que requiere unas buenas acciones de manejo para su éxito en la práctica.

Palabras clave: Projeto de Extensão. Desenvolvimento. Gerenciamento de Projeto. Metodologias Ágeis. Integración 
Práticas agroecológicas em operações do Projeto Rondon do Instituto Federal sudeste de Minas Gerais Campus Rio Pomba

\section{INTRODUÇÃO}

De acordo com Koscianski (2006) o objetivo da metodologia Scrum é fornecer um processo conveniente para projeto e desenvolvimento orientado a objeto. O Scrum apresenta uma abordagem empírica que aplica algumas ideias da teoria de controle de processos industriais para o desenvolvimento de softwares, reintroduzindo as ideias de flexibilidade, adaptabilidade e produtividade. O foco dessa metodologia é encontrar uma forma de trabalho dos membros da equipe para produzir o software de forma flexível e em um ambiente em constante mudança.

Kniberg (2007) ressalta que o desenvolvimento de softwares envolve muitas variáveis técnicas e do ambiente, como requisitos, recursos e tecnologia, que podem mudar durante o processo. Isto torna o seu desenvolvimento imprevisível e complexo, requerendo flexibilidade para acompanhar as mudanças. O resultado do processo deve ser um projeto que seja realmente útil e necessário para o cliente.

Já, SCHWABER e SUTHERLAND (2013) dizem que, o Scrum não é uma metodologia é um framework ${ }^{1}$. O que significa que Scrum não vai te dizer exatamente o que fazer e sim irá te forçar a adaptar o processo para a sua situação especifica.

Pedrazzi e Yamamoto (2013) destacam que para as ações do projeto de extensão bem articuladas se faz necessário um planejamento estratégico, isto é, o perfeito engajamento entre o líder e a equipe. Outro ponto interessante no ponto de vista desses autores é sobre a importância de se obedecer ao binômio: "Responsabilidade de cada um e o comprometimento de todos". Isso resulta em uma integração simbiótica ou de mutualismo para que se possam atingir os melhores objetivos propostos.

O objetivo da elaboração deste artigo é embasar o leitor sobre o que é a metodologia de gerenciamento de projetos Scrum e qual é a finalidade da mesma, além de expor um relato na visão de um universitário sobre um renomado projeto de extensão (denominado Projeto Rondon) conceituado e de grande importância em nível nacional, que necessita da aplicação de uma metodologia para um bom gerenciamento de ações e desenvolvimento. Para tal, será exposta a situação em que o projeto foi desenvolvido antes da implantação da metodologia, as dificuldades enfrentadas, terminando com a análise dos resultados e uma possível conclusão sobre o impacto da implantação da metodologia dentro do processo de desenvolvimento.

Para viabilizar esse relato, utilizou-se como base a pesquisa e observação direta, análise de documentos pertinentes ao projeto de edições anteriores que foram aprovadas, diálogos com

\footnotetext{
${ }^{1}$ No contexto do artigo, esse termo significa caixa de ferramentas.
} 
Práticas agroecológicas em operações do Projeto Rondon do Instituto Federal sudeste de Minas Gerais Campus Rio Pomba

universitários e docentes que já tinham participado do mesmo em edições anteriores e pesquisas em diversos sites para embasar e enriquecer a ideia principal do artigo.

\section{MATERIAL E MÉTODOS}

A principio o desejo de ser rondonista ${ }^{2}$ iniciou-se em virtude de uma palestra na Semana de Recepção de Calouros (semana de recepção dos novos alunos que iriam ingressar na Faculdade de Tecnologia de Jundiaí - Deputado Ary Fossen no ano de 2013), essa palestra foi sobre a Operação 2 de Julho, onde 8 alunos de cursos multidisciplinares sob a supervisão de 2 docentes retornavam de uma experiência fantástica e de extensão que agregou muitos valores e conhecimentos a equipe.

Após um ano, em meados do mês de Abril de 2014, deu-se inicio a uma expedição ao desenvolvimento de uma proposta de trabalho que seria submetido à plataforma da comissão julgadora do Projeto Rondon, localizada na Esplanada dos Ministérios, no Bloco Q, no estado de Brasília.

Segundo o sitio oficial, o Projeto Rondon é coordenado pelo Ministério da Defesa, esse projeto de integração social que envolve a participação voluntária de estudantes universitários na busca de soluções que contribuem para o desenvolvimento sustentável de comunidades carentes e aumento do bem-estar da população.

O projeto é realizado em parceria com diversos Ministérios e tem o apoio das Forças Armadas, que proporcionam o suporte logístico e a segurança necessários às operações. Conta, ainda, com a colaboração dos Governos Estaduais, das Prefeituras Municipais e de empresas socialmente responsáveis.

As ações do projeto são orientadas pelo COS (Comitê de Orientação e Supervisão do Projeto Rondon), criado por Decreto Presidencial de 14 de janeiro de 2005. Ele é constituído por representantes dos Ministérios da Defesa, que o preside, do Desenvolvimento Agrário, Desenvolvimento Social e Combate à Fome, Educação, Esporte, Integração Nacional, Meio Ambiente, Saúde e pela Secretária-Geral da Presidência da República.

Com a divulgação do convite no sitio oficial do projeto é iniciado o processo de pesquisa. A princípio existia um grande volume de informações e com a orientação da coordenadora de

\footnotetext{
${ }^{2}$ Termo empregado aos acadêmicos das IES (Instituição de Ensino Superior), ou seja, aos estudantes que
} realizam e desenvolvem o projeto. 
Práticas agroecológicas em operações do Projeto Rondon do Instituto Federal sudeste de Minas Gerais Campus Rio Pomba

projetos institucionais, começou o processo de analise e seleção das informações que iriam compor a proposta de trabalho.

Depois de concluída, em meados de maio do mesmo ano, foi feita a submissão da proposta para a analise, e aproximadamente no mês de julho, teve-se o feedback positivo, onde era visível a aprovação da proposta pela comissão do projeto.

Diante disso, começou o desenvolvimento das oficinas. No entanto, houve problemas de adaptação de horários para o desenvolvimento, pois ao mesmo tempo em que o período letivo estava ativo, era necessário desenvolver cada ação que fazia parte da composição do projeto.

Em meados de novembro, uma das docentes representando a IES, saiu em expedição para a viagem precursora ${ }^{3}$ e em seu retorno trouxe informações valiosas sobre o município e de como seria realizado o projeto. Tanto que, acabou assumindo a função de coordenadora da equipe. A partir desse momento houve a necessidade de realizar adaptações na proposta de trabalho.

Em dezembro do mesmo ano, encerrava-se o ano letivo e a partir desse momento a parte de desenvolvimento tornou-se mais efetiva, tomando um rumo mais veloz. A somatória de todas as orientações refletiu no sucesso das oficinas.

No dia 16 de Janeiro de 2015, inicia-se a jornada rumo a Operação Jenipapo ${ }^{4}$, com destino ao Centro Regional, localizado em São Luís. Depois de desembarcar, a recepção foi muito bacana com a ilustre presença da figura "Anjo" e a partir daquele momento, era perceptível em meio ao horizonte o inicio de um sonho.

Durante dois dias, o alojamento era na sede regional, o batalhão do exército $24^{\circ} \mathrm{BIL}$, esse momento permitiu o contato com diferentes rondonistas que também iriam para municípios distintos desenvolver seus projetos. Esse momento foi ideal para a realização de troca de

\footnotetext{
${ }^{3}$ É uma viagem feita por um (a) dos (as) docentes que supervisionarão a equipe durante a parte pratica do projeto onde é apresentada a proposta de trabalho a prefeitura do município, onde serão desenvolvidas as ações, com participação de autoridades municipais e demais envolvidos. É um momento em que a representante da faculdade alinha as questões de alojamento da equipe, recursos e materiais necessários para a difusão das oficinas no município, alimentação, locais em que serão sediadas as ações, entre outros. Além disso, é o momento de conhecer e firmar contato com o (a) outro (a) docente da equipe que compõe o outro bloco de ações para desenvolvimento das atividades no município, ao final desse período os docentes que participaram da viagem precursora recebem o título de Coordenadores da Equipe, pois, serão eles que manterão a ponte de contato entre prefeitura do município contemplado com o projeto e Governo Federal.

${ }^{4}$ A Operação "Jenipapo" foi desenvolvida em 15 municípios do Maranhão, entre os dias 18 de janeiro e 01 de fevereiro de 2015, tendo como Centro Regional a cidade de São Luís/MA, e envolveu, em princípio, os seguintes municípios do Estado do Maranhão: Alto Alegre do Pindaré, Anajatuba, Anapurus, Arari, Axixá, Cajapió, Icatu, Mata Roma, Matinha, Matões do Norte, Monção, Morros, Santa Rita, São Mateus do Maranhão e Tufilândia.

5 Termo carinhoso utilizado para o sargento do exército que acompanha e preserva a segurança dos rondonistas no município que irá receber o projeto.
} 
Práticas agroecológicas em operações do Projeto Rondon do Instituto Federal sudeste de Minas Gerais Campus Rio Pomba

experiências e conhecimentos multidisciplinares, como também, para conhecer a equipe da Universidade Comunitária de Chapecó, UNOCHAPECÓ - SC (equipe que desenvolveu atividades em conjunto com a Fatec Jundiaí - Deputado Ary Fossen).

Chegando ao município de Arari, foi necessário ir se adaptando as varias situações que apareciam, de forma ágil e veloz. Temos, como exemplo, a questão da oficina "O poder da motivação": estávamos com a falta de infraestrutura e público para ministrar a oficina, percebendo a situação três rondonistas e com o apoio muito assertivo das docentes que supervisionavam os trabalhos, em um processo logístico muito bem sincronizado conseguimos montar de forma dinâmica o que tinha sido projetado e com os recursos que estavam disponíveis no momento. Ou seja, não deixando morrer o espírito rondonista e chegar a ponto de cancelamento da oficina. Além do mais, tivemos a participação especial de um dos rondonistas de medicina que contemplava a equipe do bloco A, somando e enriquecendo ainda mais o conteúdo da oficina.

Com isso, fomos às ruas do município para tornar mais efetivo o processo de divulgação das atividades que seriam executadas, e para atrair o maior número possível de público. Entretanto, isso foi uma grande dificuldade, principalmente, nas ações sobre saúde, houve uma barreira quanto ao envolvimento da população local em relação a essas ações.

Frente à situação, a junção de rondonistas das duas equipes foi necessária para avaliar todas as outras atividades já realizadas e verificar a possibilidade de encontrar uma solução para essa situação. Após essa articulação tivemos como resultado um degrau chamado sucesso.

Podemos dizer que esse processo de união entre os rondonistas. , foi tão sinérgico que ao final de cada ação, dava-se para compartilhar aqueles momentos gratificantes e que simplesmente sintetizavam a magia e o calor sentimental daquela terra sagrada.

Outro ponto que merece atenção foi na oficina que tinha como ferramenta de trabalho Prezi, no dia em que foi aplicada essa oficina, aconteceu mais uma vez, um pequeno problema quanto à participação do publico alvo esperado. Em um primeiro momento, a somatória do publico ali presente era de somente três pessoas. Logo, surgiu a ideia de ir á Secretaria de Assistência Social e com um dialogo com a responsável do órgão público do município. Imediatamente, a mesma acolheu a causa e cedeu o espaço da secretaria para realizar a oficina, como também mobilizou os funcionários para participarem da atividade, totalizando um numero final de 12 pessoas presentes e uma boa aceitação do publico.

Os bastidores (processo de organização das oficinas) eram muito animados, isto porque, era o momento que os rondonistas se divertiam e a integração era simplesmente fantástica, conforme ilustrado na figura 1. 
Práticas agroecológicas em operações do Projeto Rondon do Instituto Federal sudeste de Minas Gerais Campus Rio Pomba

Por fim, conclui-se que durante os dezenove dias que ficamos empenhados transmitindo conhecimento, construindo novos laços de amizade, foi possível entrar em contato com uma realidade totalmente diferente, rica em cultura e afeto.
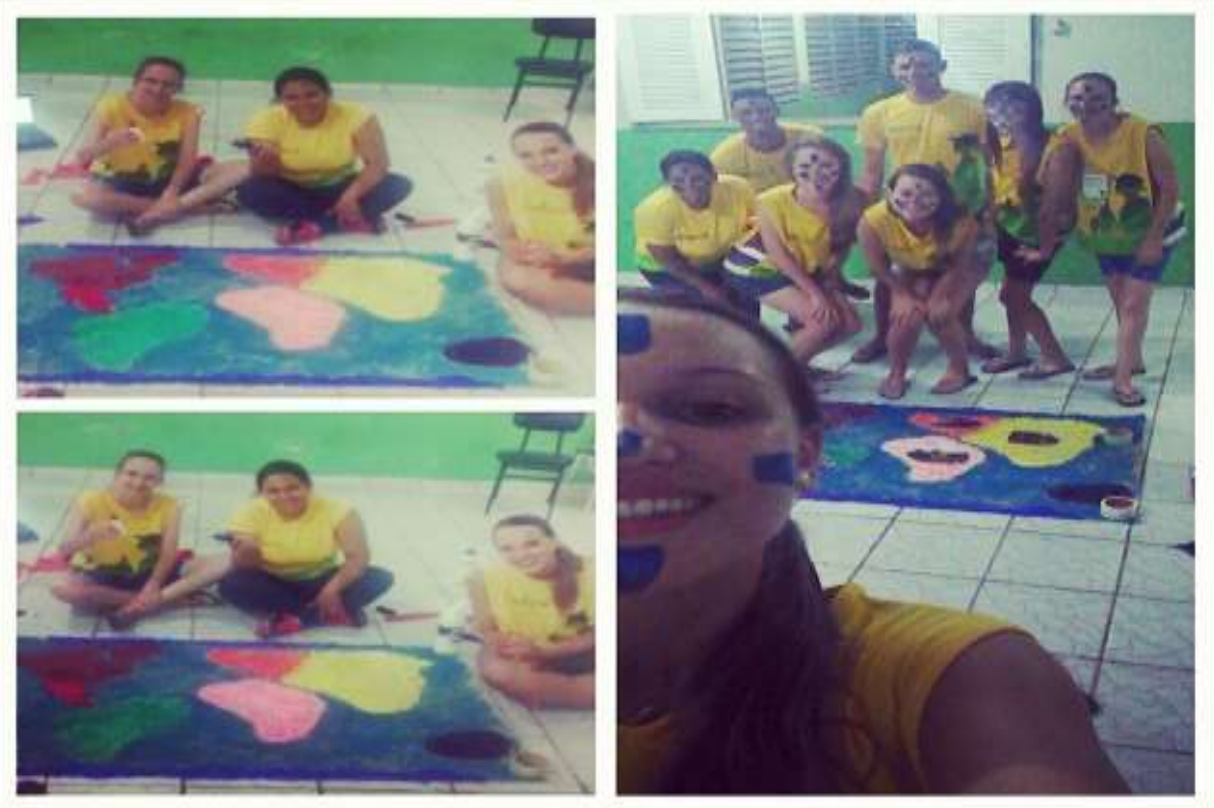

Figura 1 - Integração entre os rondonistas Fonte: Elaborado pelos autores, 2015.

\section{RESULTADOS E ANÁLISE}

Após a aplicação das oficinas e a analise posterior das atividades desenvolvidas, foi observado que as oficinas que trabalhavam com a ferramenta Prezi, a de motivação e a caminhada ecológica, ao mesmo tempo em que sintetizaram conhecimentos da comunidade local, permitiram aos rondonistas tirar uma infinidade de lições e reflexões para a construção de um pensamento mais critico.

Prezi é uma ferramenta tecnológica e dinâmica fundamental para auxiliar nas reuniões dos conselheiros da prefeitura local. Também, foi um recurso muito efetivo na apresentação de resultados gerados pela secretaria de ação social do município decorrente de programas da esfera federal, além de contribuir massivamente no eixo da educação, para o desenvolvimento multidisciplinar, como na forma de comunicação dos universitários da região. Essas conclusões foram obtidas também pelo fato da participação em uma oficina ministrada pelos acadêmicos do bloco A, dedicada aos conselheiros da região, os diálogos e conhecimentos que ali estavam 
Práticas agroecológicas em operações do Projeto Rondon do Instituto Federal sudeste de Minas Gerais Campus Rio Pomba

presentes revestiu a construção de um pensamento mais didático e que serviu como base para ilustrar ainda mais o conteúdo da oficina.

A oficina que tinha por tema motivação visou reunir os profissionais, principalmente, do setor público e trazer uma nova maneira de esquecer por um momento sua rotina. Isso foi possível, por meio de atividades lúdicas, resgatando sorrisos apagados por desmotivação e no mais trazer a reflexão que devemos sempre dar um start em nossa vida, sendo esse o combustível primordial que ajudará a florescer a motivação e o gosto pelo que fazemos.

Outra que teve destaque na forma que foi ministrada foi à oficina de empreendedorismo, teve uma boa aceitação, principalmente, pelos universitários e secretários de turismo da região. Foi aproveitado o tema da motivação e criamos dentro dessa oficina uma analogia onde abordava o conceito empreendedor juntamente com o recurso de vídeos motivacionais, foi simplesmente unir o útil ao agradável.

Além disso, a atividade da caminhada ecológica teve um caráter bem bacana, pois, com o apoio constante da professora que nos supervisionava e do secretário de meio ambiente do município, foi arrecadado mudas nativas da região e disponibilizado um local de preservação para o devido plantio dessas mudas. Por meio de um caça ao tesouro (analogia criada para fazer uma dinâmica distinta diferenciando da maneira formal de fazer o plantio), o publico tinha que caçar buracos e fazer o plantio dessas mudas e assim que todos o tivessem realizado, uma das rondonistas do curso de Gestão Ambiental, dialogava sobre a importância da preservação ambiental. A principio, tínhamos um publico pequeno de 6 pessoas, então resolvemos ir até um colégio próximo do local onde iríamos realizar a dinâmica, e conseguimos aumentar esse número para 35 pessoas.

Nas comunidades rurais as emoções e resultados foram mais intensos, em contato com a comunidade era possível transmitir conhecimentos e adquiri-los de forma proporcional. Em suma, o lado infantil dos rondonistas foi um incremento muito importante, ou seja, fez com que o rondonista saísse da sua zona de conforto e vestisse um personagem que naquele mágico momento a recompensa pudesse ser um belo sorriso estampado no semblante daquelas crianças. E mais, que esse momento pudesse também amenizar o sentimento de saudade dos nossos familiares. Conforme ilustrado na figura 2.

Analisando esses resultados e com base nos fundamentos do tópico Extensão Universitária e a Formação Acadêmica, Ricardo e Mafra (2013) mencionam que a extensão universitária do projeto Troca de Saberes permite a expansão dos horizontes do pensamento ao colocar acadêmicos em contato com experiências que os fazem refletir profundamente sobre valores e aspectos da dinâmica social. Esses autores conseguiram trazer de forma harmônica o 
Práticas agroecológicas em operações do Projeto Rondon do Instituto Federal sudeste de Minas Gerais Campus Rio Pomba

verdadeiro sentido da extensão universitária dentro da vida acadêmica do universitário. E ainda com a bela explicação de FREIRE (1983), que aborda que essa experiência permite ao estudante ter a oportunidade de vivenciar um momento de aprendizado que vai além da cadeira acadêmica em uma relação direta com a sociedade, sintetizam a verdadeira concepção do espírito extensionista.

Temos que levar em consideração que o Projeto Rondon, tem uma estrutura muito grande e conta com o apoio dos seus parceiros, as IES e prefeituras dos municípios que irão receber o projeto. A presença do Scrum partindo de dentro da Instituição de ensino já seria uma forma de contribuir massivamente para o desenvolvimento assertivo da proposta de trabalho, como também, de verificar a assiduidade e o comprometimento dos acadêmicos com o projeto. No mais, isso evitaria a possibilidade de desistência do compromisso e custo adicional à comissão do Projeto.

Outra premissa que permitiu chegar a essa conclusão, foram os números de operações anteriores, percebemos que o número total de participantes acaba sendo diferente do projetado e muitas vezes, esses participantes acabam desistindo num momento muito delicado, ou seja, em um prazo que já não é possível fazer a devida substituição do participante. Uma forma de amenizar esse desfecho seria utilizar a didática da caixinha de moedas e notas do Scrum, aplicado a este artigo, caso o participante viesse desistir pagaria uma multa com o respectivo valor dos custos gastos pela comissão do projeto e seria advertido dentro do ambiente acadêmico por tirar a oportunidade de outro estudante. Poderia também ser homologada e implantada dentro do convite de abertura que convida as IES a participarem do projeto com as devidas aprovações do Coordenador Geral do Projeto Rondon e do Comitê de Orientação e Supervisão do Projeto Rondon - COS.

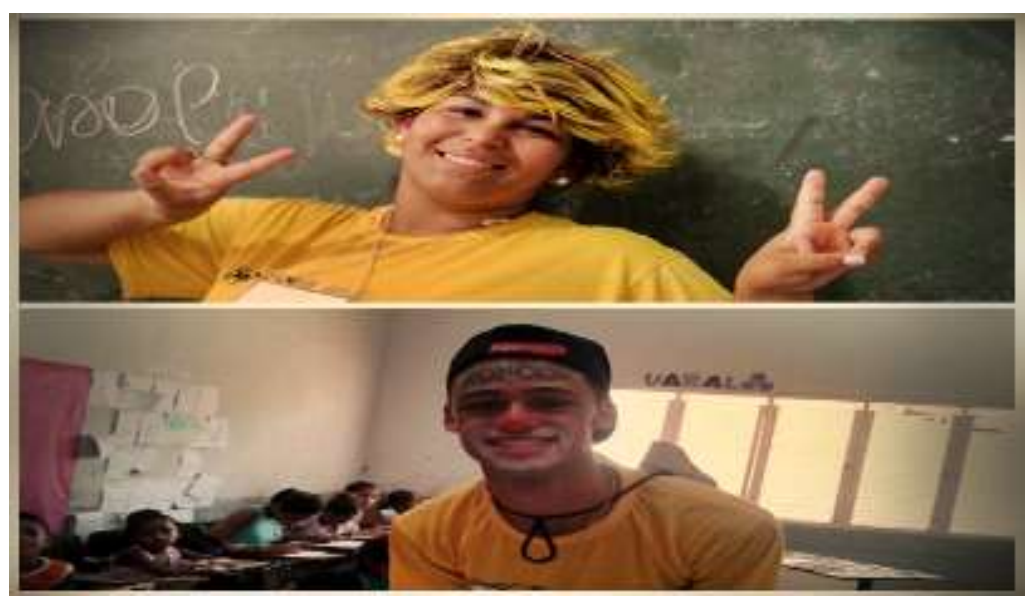

Figura 2 - Representação dos personagens criados pelos rondonistas na comunidade rural Fonte: Elaborado pelos autores, 2015. 
Práticas agroecológicas em operações do Projeto Rondon do Instituto Federal sudeste de Minas Gerais Campus Rio Pomba

\section{CONSIDERAÇÕES FINAIS}

Em fevereiro de 2015, no final da parte prática do projeto, após dez meses do inicio do projeto, o resultado foi muito positivo quanto ao aproveitamento das oficinas, principalmente, as que tinham relação com os temas de turismo, tecnologia e meio ambiente, pois, as mesmas retratavam a necessidade que o município tinha em relação a essas áreas.

Além disso, a junção de algumas atividades com a equipe que contemplava o bloco $\mathrm{A}$, foi fundamental para amadurecer um relacionamento sadio e sinérgico entre os rondonistas. No mais, retratou um laço de amizade que fez toda a diferença tanto no desenvolvimento das atividades do projeto como na esfera afetiva de sentimentos.

Para que todo esse processo de desenvolvimento fosse mais efetivo, não podemos dispensar a presença de um bom gerenciamento de projetos. A presença do Scrum, dentro do contexto abordado trouxe um melhor aproveitamento e organização no decorrer do desenvolvimento da proposta de trabalho. A relação entre os stakeholders ${ }^{6}$ foi mais dinâmica e os erros e atrasos diminuíram. Sabemos que na prática as coisas não ocorrem como o planejado, porém, se houver dedicação e muita iniciativa perante as adversidades, a chave do sucesso será garantida.

Conclui-se que a experiência com projetos de extensão despertou o espírito solidário e fraterno junto ao próximo, onde a pré-disposição da sociedade em debater situações de seu interesse, sendo essas discussões orientadas e amparadas tecnicamente pelos acadêmicos permitiu ganhar uma bagagem imensa de conhecimento e reflexão. Nesse sentido, sob o prisma da construção coletiva do saber, conectado com a vontade de querer fazer o melhor, reflete marcas que jamais o tempo poderá apagar e reforça ainda mais o compromisso da universidade com a sociedade para a difusão do seu desenvolvimento.

\section{REFERÊNCIAS}

BRASIL. Ministério da Defesa. Projeto Rondon. Disponível em: < http://www.defesa.gov.br/projeto rondon >. Acesso em: 11 jun. 2015.

\footnotetext{
60 termo stakeholder foi criado por um filósofo chamado Robert Edward Freeman. Esse termo pode ser atribuído a uma pessoa ou um grupo, que legitima ações de uma organização e que tem o papel direto ou indireto na gestão e resultados dessa mesma organização/equipe.
} 
Práticas agroecológicas em operações do Projeto Rondon do Instituto Federal sudeste de Minas Gerais Campus Rio Pomba

Ministério da Defesa. Projeto Rondon. Disponível em: <projetorondon.paginaoficial.com/portal/>. Acesso em: 30 jun. 2015.

Ministério da defesa. Relatório da VII Reunião Anual de Professores do Projeto Rondon. Disponível em: $\quad<$ http://projetorondon.paginaoficial.com/portal/index/downloads/categoria/47740/module/default $>$. Acesso em: 30 jun. 2015.

FREIRE, P. Extensão ou Comunicação? Rio de Janeiro: Paz e Terra, 1983.

KNIBERG, H. Scrum e XP direto das trincheiras: como nós fazemos scrum. Editora INFOQ, 2007.

KOSCIANSKI, A; SOARES, M. S. Qualidade de Software: aprenda as metodologias e técnicas mais modernas para o desenvolvimento de software. São Paulo: Editora Novatec, 2006.

PEDRAZZI, V.; YAMAMOTO, M. M. A necessidade de ações articuladas na cultura e extensão. Revista de Cultura e Extensão da USP, v.10, p. 43-50, nov. 2013.

RICARDO, G. S.; MAFRA, A. L. Perspectivas da Extensão Universitária no projeto troca de saberes da Universidade do Estado de Santa Catarina (UDESC). Revista de Cultura e Extensão da USP, v.10, p. 43-50, nov. 2013.

SCHWABER, K.; SUTHERLAND, J. Guia do Scrum. Disponível em: $<$ http://www.scrumguides.org/docs/scrumguide/v1/scrum-guide-portuguese-BR.pdf $>$. Acesso em: 13 jun. 2015. 